This is the final author draft of an article published in the British Journal of Social Work (2007) 37, 2, 209-224. Advance access published online on 13 March 2006 by Oxford Journals on behalf of the British Association of Social Work and available online at http://bjsw.oxfordjournals.org/cgi/content/abstract/bcl012v1

Article title:

THE REGULATION OF OUT-OF-HOME CARE

Author name:

Biographical note:

Address:

Email:

Word length:
Clare Tilbury

Clare Tilbury (BSocWk, MPhil, PhD) is a Senior Lecturer at the School of Human Services at Griffith University in Australia.

School of Human Services

Logan campus, Griffith University

University Drive

MEADOWBROOK QLD 4131

c.tilbury@griffith.edu.au
Abstract 100 words
Body text $\quad 5,722$ words
References 1,059 words 


\begin{abstract}
THE REGULATION OF OUT-OF-HOME CARE

The regulation of out-of-home care in Australia has become increasingly formalised and detailed, partly driven by a recent wave of audits of abuse in foster care. The emergence and possible consequences of this increased regulation are examined, with a particular focus on relative care. A pluralist-democratic approach to accountability would involve a regulatory regime linked to other quality strategies, with the emphasis on improved quality and outcomes rather than compliance with policy and procedures. The concentration on expanding the regulatory regime is contrasted with more limited efforts to improve carer support, an essential ingredient of an effective foster care system.
\end{abstract}

Keywords: regulation, accountability, foster care 


\section{THE REGULATION OF CARE}

\section{Introduction - the regulatory state}

There are many signs of the growth of the 'regulatory state' (Hoggett, 1996) in child welfare services in Australia. Audits, inquiries, standards, charters, approvals, certification, quality assurance, performance indicators, and inspections of various types are now commonplace. The legislation, policy and procedures for assessing, monitoring and reviewing out-of-home care arrangements for children have become increasingly formalised and detailed. The growth of regulation is particularly evident in foster care (the predominant type of out-of-home care), impelled by amassing evidence of poor standards of care, including abuse of children by some carers. This attention to regulation stems from a desire to manage the risks inherent in out-ofhome care, to raise the quality of services, and make the care system more accountable. Changes to the regulatory regime might be necessary, even overdue, in order to achieve greater transparency and a line of control from service providers to government. This would be consistent with a managerial or procedural model of accountability 'upwards' (Sanderson, 1998). But it leaves open the question of whether increased regulation is effective in improving quality and outcomes. A more pluralist-democratic model of accountability involves both political and social obligations and the protection of consumer interests (Carter et al., 1992; Sanderson, 1998). This broader conceptualisation of accountability 'outwards' points to the need to consider the role of regulation in improving the quality of foster care and making it more accountable to children and young people in out-of-home care, and their parents.

The purpose of this article is to discuss the emergence and possible consequences of the regulation of out-of-home care. It pays special attention to 'relative' or 'kinship' care, which 
involves children who are subject to statutory intervention being looked after by extended family members. Relative care is especially relevant to Aboriginal and Torres Strait Islander children in Australia, for they are six times more likely to be in care and more likely to be placed in relative care than non-Indigenous children. Between 16 per cent and 55 per cent of all children in out-of-home care were placed with relatives in 2004 (depending on which State they lived in) and the proportion was greater for Indigenous children than for non-Indigenous children in all jurisdictions (Steering Committee for the Review of Commonwealth/State Service Provision, 2005, p.15.21). Moreover, the extended family network has a special significance in Aboriginal and Torres Strait Islander constructions of family and child rearing, making relative care more culturally appropriate (Batrouney and Soriano, 2001; Stanley et al., 2003). The article considers the context in which increased regulation is occurring, the nature of regulatory regimes being constructed in out-of-home care, and the particular difficulties with using regulation to improve quality in relative care.

\section{The rise of regulation}

There are three characteristics of regulation within government. Firstly, it involves the attempt by one entity to control or modify the behaviour of another - it has an inter-organisational dimension, rather than 'line management' control. Secondly, regulators are separate from units with direct operational or service delivery responsibilities, having centralised oversight powers. Thirdly, regulators have an official mandate to scrutinise the behaviour of regulatees, with the aim of serving the public interest (Ashworth et al., 2002; Walshe, 2003). This article is concerned with regulation beyond that provided by courts and legislation (primary regulators) and discusses secondary or 'arms-length' regulation, in which standard-setting and information gathering are the main tools used to control or modify behaviour (Hood et al., 1998). 
There has been an increase in the formality, complexity, intensity and specialisation of regulation over the past two decades (Hood et al. 1998). Terms such as the 'regulatory state' (Hoggett, 1996), the 'audit society’ (Power, 1997) and the 'evaluative state’ (Henkel, 1991) have been used to conceptualise this growth, which is linked to new public management and neo-liberal forms of governance which have placed 'the lessening of risk, not the meeting of need' at the centre of social policy (Culpitt, 1999, p.35). Decreasing trust in government and the professions has lead to greater demands for accountability, and since government is 'steering, not rowing', indirect forms of control are required. Power (1997) argues that the transformation of the public-private divide via new public management is a precondition for the 'audit explosion', which is primarily concerned with securing legitimacy for organisational action. The information-gathering, measuring and checking processes of regulation provide assurance that government is properly managing risk. But the institutionalisation of audit - 'checking gone wild' - is mostly about producing comfort and hiding real risk, making audit a 'shallow ritual of verification' undertaken at the expense of real organisational intelligence (Power, 1997). When government uses regulation to protect itself from criticism, paradoxically, the growth of audit and regulation can actually undermine trust in government, rather than increase trust.

\section{Problems with regulation}

Regulation can be expensive, involving both the direct costs of funding and staffing regulatory bodies, and the indirect or compliance costs for the entities that must conform to standards and demonstrate they have conformed. Empirical research on regulatory regimes has revealed a set of common problems (Ashworth et al., 2002), including: 
- Resistance by regulatees, as they attempt to undermine the process of regulation in order to retain their autonomy;

- Ritualistic compliance - as regulation has a role in the production of organisational legitimacy, if formal audit practices are separated from substantive organisational processes, there is a risk of mechanistic compliance ('ticking the boxes'). This may disguise underlying problems of policy or administrative failure;

- Regulatory capture, whereby regulators are unable or unwilling to take action if standards are not met. This can happen particularly when consumers do not have a voice in regulatory regimes (Kerrison and Pollock, 2001);

- Performance ambiguity, which arises when 'good' standards cannot be clearly established; and

- Data problems - even when performance standards are clear, there may be difficulty in measuring compliance if adequate data are not available.

Hood et al. (1998) caution that regulation has grown because less formal systems of control have failed or weakened. They contend it is not a matter of too much regulation, but that regulatory ties need to be co-ordinated with other quality and accountability mechanisms. This would involve less reliance on the 'search every suitcase' strategy, instead moving to more self-regulatory models, including more efficient (but no less effective) random checking methods that decrease bureaucratic routines but increase the overall regulatory effect. They argue that regulation has grown like topsy and lacks reflexivity. Regulation is taken to be good, regulators themselves are not exposed to systematic scrutiny, and the costs of regulation are assumed to be worthwhile (Hood et al., 1998). The literature suggests the challenge with regulation is to strike the right balance between conformance (conforming to the rules) and performance (achieving results). These theoretical understandings and empirical findings on 
the rise of government regulation in the contemporary context provide the foundation for an examination of the domain of out-of-home care and the regulatory regimes developed for these services in Australia.

\section{Domain of out-of-home care}

In Australia, children in out-of-home care are generally subject to a court order placing them in the guardianship of the State, but they may also be placed with parental consent. Foster care is now the predominant type of out-of-home care, having overtaken a reliance on residential care in most jurisdictions, including Australia (Triseliotis et al., 2000; Gilbertson and Barber, 2004; Steering Committee for the Review of Commonwealth/State Service Provision, 2005). Relative care is a type of foster care in which a child is both a 'client' of the statutory agency and, for example, a grandchild or niece or nephew, often being cared for alongside other children not in care. Carers are recruited, trained and supported by child welfare workers in either the statutory agency or non-government foster care agencies. Both foster carers and relative carers must be approved by the statutory agency as suitable to provide care. In Australia they are mostly volunteers, not paid staff, who receive an allowance to reimburse the costs of care. It is generally acknowledged that allowances do not meet the full costs of care and that carer families make significant contributions to the costs of looking after children (McHugh, 2002).

Internationally, the quality of out-of-home care, the availability of placements and support for carers have become urgent issues for government to address (Fisher et al., 2000; Crime and Misconduct Commission, 2004). Many of the problems of quality in out-of-home care are long-standing ones. They include the damaging effects of moving from one temporary placement to another, a lack of planning leading to children drifting in out-of-home care with 
an uncertain future, and indifferent attention to their health and educational needs (Parker et al., 1991). But there are other, more recently arising, problems in out-of-home care. The volunteer system of foster care relies on outdated normative assumptions of two-parent, single-income households with the mother at home. As women have increasingly entered the paid workforce, foster care following this model is in decline. Carers are ageing and there are more single carers, although women still predominate (McHugh, 2005). There are problems with both recruitment and retention (Fisher et al., 2000). The consequent loss of placement choice results in difficulties matching an individual child with a carer family, which is central to stability and other successful placement outcomes (Thoburn and Sellick, 2002). Care is taking place in a context in which demand for placements greatly outstrips supply, so a placement may not be optimally matched to the needs of an individual child, but the 'best available’.

Providing foster care is very difficult and requires considerable skills, including the ability to empathise with the child and understand the problems in the birth family. Children increasingly present with challenging behaviours and complex needs arising out of their experiences prior to coming into care and the effects of the care experience itself (Triseliotis et al., 2000; Thoburn and Sellick, 2002). These behaviours may include stealing, lying, inappropriate sexual behaviours towards other children, physical and verbal abuse, and destroying property (Sinclair and Wilson, 2003). Children may want to remain with their parents despite the troubles that led to them coming into care, and ongoing contact between the child and their parents has been found to be important to both the child's well-being and placement stability (Cashmore and Paxton, 1996; Thoburn and Sellick, 2002). As a result of placement, a child may be separated not only from parents but also from siblings, neighbourhood friends and grandparents. Such dislocations can result in a child being 
deprived of a sense of belonging and identity forged from experiences of family, community, cultural and school ties, with negative consequences flowing on into adulthood (Stevenson, 1992).

\section{Rise of relative care}

It is against this backdrop that more attention has been directed to relative care, and not only as a consequence of the declining supply of traditional carers. The development of the knowledge base regarding the importance of attachment, a sense of belonging and stability for children, challenges to 'dysfunctional family' theories in favour of ecological and strengthsbased models, and favourable outcome studies have also led to children in care increasingly being placed with relatives (Flynn, 2002). In Australia, the proportion of children placed with relatives is a national performance indicator for child protection and out-of-home care services (Steering Committee for the Review of Commonwealth/State Service Provision, 2005). The rationale for favouring relative care is based on factors such as it being less of an upheaval for a child to be placed with someone known to them; relative placements being less likely to sever children's connections with their family and community; relative placements tending to be more stable and facilitating ongoing parental contact; siblings being more likely to be placed together; and relative placements being more likely to be culturally appropriate (Scannapieco et al., 1997; Ainsworth and Maluccio, 1998; Testa and Rolock, 1999; Flynn, 2002). Placement with relatives enables the child to maintain a sense of belonging within their family of origin; and relatives are more likely to have, or to form, long-term emotional bonds with the child (Broad et al., 2001; Flynn, 2002).

Giving added impetus to the preference for relative care in Australia is a desire to improve outcomes for Aboriginal and Torres Strait Islander children in the child welfare system. Both 
past and current government child welfare policy and practice has had the effect of separating Indigenous children from their families and culture, with deleterious long-term impacts (Human Rights and Equal Opportunity Commission, 1997). Since 1984, the policy of all Australian States and Territories has been to place Indigenous children with relatives whenever possible in accordance with the Aboriginal and Torres Strait Islander Child Placement Principle (Ah Kee and Tilbury, 1999). As well as its benefits as a family preservation strategy to maintain family and cultural ties, relative care is consistent with existing and traditional patterns of extended family involvement in child-rearing (Human Rights and Equal Opportunity Commission, 1997). Aboriginal and Torres Strait Islander children are more likely to be placed with relatives than are non-Indigenous children (Steering Committee for the Review of Commonwealth/State Service Provision, 2005). This is similar to the situation in the USA where kinship care is predominantly used by African-American children (Scannapieco et al., 1997).

However relative placements may not always be the best option. There are concerns about the quality of care including the safety of children, and the difficulty of negotiating long-standing family dynamics that may undermine the pursuit of case goals such as reunification (Ainsworth and Maluccio, 1998; Peters, 2005). Depending on the individual circumstances of children, it may be more important to have (for example) a local placement that enables continuity at school rather than a distant placement with relatives. And while relative placements tend to be more stable and provide ongoing ties with family and culture, research has found that relative carers tend to receive less training and support than other foster carers (Ainsworth and Maluccio, 1998; Children's Defense Fund, 2000); to have fewer social and economic resources (Cuddeback, 2004); and to be unsure of their entitlements to support (Broad et al., 2001). While acknowledging the positive aspects of relative care, the literature 
suggests that unless placements are adequately monitored and supported, they are unlikely to provide a quality care experience for children (Cuddeback, 2004). More examination of relative care placements, including how they are supported and regulated, is warranted.

\section{Recent audits}

There has been a spate of 'abuse in care audits' carried out in Australian child protection jurisdictions in the past few years. Victoria conducted an audit of clients in relative care in 2000 with the aim of improving policy and practice in relation to all aspects of relative care. This audit led to a more formal and consistent assessment process as well as changes to training, supervision and payment (Child Protection and Juvenile Justice Branch, 2000). In Western Australia in 2004 an independent review was conducted of the adequacy and strength of systems and processes for managing abuse in care. This resulted in more rigorous assessment of relative carers, training, quality assurance, a statement of commitment with carers, a register of carers, screening for criminal history, an increase in carer allowances and development of more placement options (Government of Western Australia, 2005). Queensland conducted an independent audit of abuse in care followed by a Crime and Misconduct Commission Inquiry (2004) resulting in major reforms including legislative provisions and new policy regarding the approval of relative carers; powers for the Commission for Children and Young People to inspect foster care homes, increases in carer allowances and more placement options. In the Australian Capital Territory an audit of abuse in care in 2004 led to more rigorous assessment of relative carers and the establishment of an out-of-home care audit unit (Minister for Children, Youth and Family Support, 2005). In South Australia a Commission of Inquiry has been established to inquire into the sexual abuse of children in State care. All of these audits and inquiries (with the exception of the last, 
which has not yet concluded) recommended making the government regulation of out-ofhome care more formal, detailed and rigorous.

\section{Regulatory regime for out-of-home care}

Consequently, the regulatory regime for out-of-home care in Australia now typically includes policy instruments and procedures such as:

- Regular checks of criminal history charges and convictions plus checks of traffic, domestic violence and child protection history for the carer, the carer's family members, and frequent visitors to the home

- Assessment of the carer and the carer's family (generally psycho-social and/or competency based approaches)

- Personal references that attest to the applicant's capacity to undertake foster care

- Issuing time-limited certificates of approval to carers

- Written placement agreements

- Enforceable standards of care in policy and legislation

- Charters setting out the rights and responsibilities of carers

- Licensing or accreditation for non-government agencies that recruit, train and support carers

- Inspections of foster care homes conducted by independent authorities (for example, ‘community visitors’ from the Queensland Commission for Children and Young People)

- Establishment of special units within statutory agencies charged with conducting audits of practice and/or investigating complaints of maltreatment by carers

- Register or database of approved carers with provision for de-registration

- Rights of appeal for carers to an external body such as the Ombudsman or the Children Services Tribunal in Queensland 
- Performance indicators requiring public reporting about the extent of abuse in care These procedures are all administered and imposed by the State. The regulatory role is not confined to the statutory agency responsible for child protection, as oversight bodies such as a Children's Commissioner or Children's Guardian may also have regulatory powers. It is noteworthy that all the audits have been concerned to bring relative care within the broader ambit of the regulatory regime for out-of-home care generally.

Foster care takes place in a very private domain - the carer's home - which gives rise to both monitoring difficulties and opportunities for abuse of power. Relative care, in particular, is obviously a difficult arena for government regulation, being a service that is simultaneously private (carried out by volunteers who, in the case of relative care, are part of the child's family) and public (carried out using government funds, on behalf the State, for a child in the care of the State). Regulation has increased in part because of the failure of less formal systems of control. Indeed, these failures are demonstrated by the findings of audits and the publication of performance data that show unacceptable levels of abuse in care or failure to provide adequate care. For example, undocumented and informal systems of assessment that did not use consistent criteria allowed unsuitable people to become approved or stay approved as carers. Many jurisdictions previously had systems of 'approval for life', now replaced by time-limited approvals. With carers becoming less compliant and more able to pursue legal avenues if they dispute decisions affecting their role as carer, there is a need for case workers to become more process-oriented to ensure fair and equitable decision-making processes. Inadequate case supervision, case review and data collection allows poor care to remain undetected. Increasing frontline workload pressure and large caseloads has meant that one of the main forms of monitoring placement quality - the casework relationship between the child, the child's family, the carer and the statutory case worker - is no longer being 
performed to the extent that it should (Gilbertson and Barber, 2004). Statutory agencies in many States have outsourced foster care recruitment to non-government agencies (wholly in some jurisdictions such as South Australia, Victoria and Western Australia, and partially in others such as Queensland), but perhaps they were not adequately prepared for their new role as arms-length regulator (Gilbertson and Barber, 2004).

\section{Limitations of regulation}

There are difficulties in attempting to address the quality problems in out-of-home care through the narrow lens of audits or inquiries. Abuse or neglect by carers is at the extreme end of problems of quality in out-of-home care and audits have not proven to be useful instruments for providing a comprehensive understanding of why poor quality persists. For example, in focusing on allegations of maltreatment and how these are dealt with, audits overlook the reasons for systemic problems such as placement instability, drift in care, failure to attend to health and educational needs, and failure to attend to cultural and identity needs. Audits and inquiries tend to be procedural, with a role of detecting mistakes, rather than developmental and addressing the underlying source of the problem. This encourages riskaverse behaviour where attention is more on process than policy objectives. As a consequence, the regulatory mechanisms that emerge from audits seek to build quality into inputs and procedures rather than entrenching values of quality and accountability to clients into the work culture.

The problems of regulation identified in the literature must be avoided. Such problems may include carers who attempt to undermine the process of regulation in order to retain their autonomy, for example, choosing not to disclose relevant information about their home situation to avoid regulatory scrutiny. There may be ritualistic compliance with the 
procedures for detecting and responding to abuse in care, but avoidance of the real problem of lack of placement options, which is a major reason why placements might be made or continued even when they are considered less than ideal. An example of regulatory capture might be when child welfare workers charged with regulation are sympathetic to carers who they perceive as doing the best they can under difficult circumstances, or they do not want to upset carers for fear that they will withdraw their services. This can lead to the interests of government, professionals or carers overriding the interests of children. Performance ambiguity is clearly a risk in the regulation of care, given the weak knowledge base for the establishment of performance indicators and standards, and even when performance standards are clear, there is difficulty in measuring compliance with available data (Munro, 2004).

Moreover, there is the difficulty of imposing formalised, institutional standards in private homes, particularly as standards have become more detailed in recent years. For example, there are often stringent requirements applied to the physical environment of foster care homes such as being smoke-free or having a fire evacuation plan that is regularly practised (Department of Human Services, 2003). This regulatory problem is not just an issue for child welfare; it arises in other areas of home-based care. This is illustrated by a recent situation in which a paid carer undertaking duties at the home of person with disability was bitten by the family dog: the workers' compensation agency found the person with the disability had failed to provide a safe workplace and sought to recover costs from the family (Weekend Australian July 2-3, 2005). It is difficult to justify standards being imported from one setting to another without due regard for context and appropriateness as being in the interests of consumers.

In the past, regulation of relative care has been less formal, less rigorous and less detailed than that of 'general' foster care (Waterhouse and Brocklesby, 1999; Triseliotis et al., 2000). 
However, as indicated above, recent audits and inquiries in Australia have tended to bring procedures for relative care into line with other types of foster care. Even if standards are 'lower' or 'different' for relative care placements (an acknowledgement that family ties might be more important to the child's well-being than the physical home environment), it would be particularly concerning if greater regulation resulted in fewer relative carers for Aboriginal and Torres Strait Islander children. Between 20\% and 60\% of Aboriginal and Torres Strait Islander children are already in culturally inappropriate placements, depending on where they live (Steering Committee for the Review of Commonwealth/State Service Provision, 2005). This raises concerns that Indigenous children may lose connections with their cultural backgrounds and traditional communities. As regulation creates more rules with which carers and prospective carers must comply, and there are more formalised procedures for enforcing rules, Aboriginal and Torres Strait Islander people may be directly or indirectly dissuaded from providing placements. Aboriginal and Torres Strait Islander people are more likely to have a criminal record, less likely to tolerate government intrusion into family life, and less likely to have the economic resources to meet standards (Stanley et al., 2003). They may also be concerned about the frames of reference that (mainly non-Indigenous) professionals use when assessing, for example, their physical home environment, their approaches to childrearing, and their suitability to become carers (Human Rights and Equal Opportunity Commission, 1997; Cunneen and Libesman, 2000). These circumstances suggest that standards should be descriptive and aspirational, rather than prescriptive and specific (Walshe, 2003). The motivations of relative carers are likely to revolve around family loyalty and preservation, and the needs of the particular child they have been asked to care for: 'they would not be expecting bureaucracy, judgement and scrutiny’ (Flynn, 2002, p. 318). The danger is that in establishing more detailed procedures and checking processes, without a broader view about quality in out-of-home care, the needs of children for safe and caring 
placements will be subjugated. Government can provide assurances that 'systems are in place' or 'proper procedures were followed' but not necessarily that children are optimally looked after. On the other hand, it has been argued that keeping relative care outside the formal foster care system has tended to marginalise it, demeaning the value of the kin relationship and denying relative carers some of the supports of the foster care system, an indication of how the care system fails to work inclusively with families (Ryburn, 1998). This points to the need for a balanced approach to the regulatory framework that recognises and appreciates the distinctiveness of relative care, consistent with a responsive or 'smart' model of regulation (Walshe, 2003). Flexibility is a hallmark of this model, providing for regulatory activities to be tailored to different circumstances, a focus on performance improvement rather than compliance, and tripartite arrangements involving regulators, regulatees and other stakeholders in regulation. Standards could emphasise the relational aspects of foster care rather than the characteristics of the physical placement setting or compliance with requirements such as compulsory training.

\section{Improving quality through carer support}

While there has been substantial government action to increase the regulation of care, including relative care, this is not matched by efforts to improve carer support in Australia, except in relation to increases in carer remuneration in some jurisdictions. This is despite the fact that research has found that relative carers would like more support, they generally do not receive as much support as other foster carers (Ainsworth and Maluccio, 1998; Gibbons and Mason, 2003), and that carer support enhances placement quality. Support improves placement quality in several ways. It enhances retention (and thereby placement choice) and improves stability by assisting carers to manage a placement (Denby et al., 1999; Waterhouse and Brockesby, 1999; Fisher et al., 2000; Triseliotis et al., 2000; Sellick and Thoburn, 2002). 
Satisfied carers are likely to recruit new ones, and 'word of mouth' is a key medium for carer recruitment (Triseliotis et al., 2000). Factors such as cultural appropriateness, keeping siblings together, and family contact (as mentioned earlier) are also proxy indicators of good outcomes from relative placements. Thus carer support is warranted on a number of grounds: the carer role is very demanding, carers provide a valuable community service, and because support improves placement stability and placement choice, both central to an effective outof-home care service.

The support needs of relative carers are substantial. Relative carers are generally not trained, they have little knowledge about their role, they may fear contact with the child welfare system and they are unlikely to participate in foster carer associations (Leos-urbel et al., 2002). Qureshi et al. (2000) caution against the stereotypical view that minority ethnic families prefer to rely on family and community supports and do not want social work help, suggesting an alternative view that many services are not culturally appropriate and that people are unaware of what is available. Since relative care in Australia is widely used, especially for Aboriginal and Torres Strait Islander children, it is important that the system does not offer lesser services to these families. Support (financial and otherwise) for relative carers is problematic because under the division of federal-state responsibilities in Australia, the federal government is responsible for income support and the States are responsible for child welfare. Yet there is a large (and apparently growing) number of people who care for the children of their relatives on an informal basis (that is, not arranged by statutory agencies) for whom there is no entitlement to State support and for whom Commonwealth support is limited. Research shows that relative carers are struggling to cope with children's difficult behaviour, their own loss of freedom, and financial worries: they want more help, but are unsure of entitlements (Broad et al., 2001, Gibbons and Mason, 2003). Relative carers also 
report difficulties in adjusting to being a full-time parent again, missing out on retirement and the physical demands of looking after children taking a toll on their health (Spence, 2004). For all carers, there are occupational hazards of providing care - disruptions to household routines and arrangements, difficulties with birth parents, or allegations of mistreatment. Such events are associated with strain among carers and often prompt them to leave. Effective support at these points is particularly important (Gibbons and Mason, 2003; Sinclair et al., 2004).

Effective carer support strategies treat carers as important partners in a shared endeavour. This means good information on children, regular and supportive contact with the child's case worker and the placement worker, opportunities to take part in training and foster carer groups, the chance to take breaks from difficult children, support out of working hours, and efficient handling of the hassles of foster care. The types of support foster carers have found to be helpful include practical supports such as respite care, financial assistance, and help with managing a child's behaviour; emotional supports such as peer support and mentoring; and facilitating or enabling assistance such as provided by a placement worker or the child's social worker (Broad et al., 2001). The professional worker role is pivotal. Workers should show an interest in how carers are managing, be encouraging, respond to requests, follow through on undertakings, keep carers informed and include them in planning, attend to the child's interests, and take account of the carer's family needs (Fisher et al., 2000). Additionally, workers may require help to deal with the family conflict that often arises as a result of relative placements and the possible higher risks associated with placing a child within the family (Peters, 2005). A lack of cultural competence to negotiate kin relationships may also militate against making good decisions (Ainsworth and Maluccio, 1998). Workers 
may feel they do not want to intrude because a child is safe and with family (Spence, 2004) but this can mean they are not actively offering a support service.

\section{Conclusion}

The evidence of poor standards in out-of-home care and the failure of the relatively informal procedures and systems of the past have provided a rationale for increased regulation. It can be argued that greater transparency in the procedures (for example, in the criteria for approval) provides a more fair and democratic regulatory regime. But to ensure accountability is not just upwards but also outwards to children and families it remains important to examine systems for the regulation of care and ask - 'good for whom?' The primary purpose of regulation should be to develop good practice rather than to obtain policy control, but there are limitations to relying on regulation to improve quality. It is not sufficient to equate quality with standardisation, documentation and measurement. A critical-pluralist approach, rather than a technical or procedural approach, could involve carer assessment and regulation through a range of means and information sources, involving dialogue with all stakeholders. It could give a formal voice to children, young people, and carers in placement decisions and case planning. The emphasis would then be on resourcing placements to enhance their quality rather than monitoring compliance with standards. Such an approach would involve a reorientation for regulation in Australia, decreasing bureaucratic routines but increasing the fit between regulatory mechanisms and other quality mechanisms. The risk management orientation at the heart of increased regulation should not drive the child welfare system; there is a clear imperative to ensure services are focused on protecting children and helping their families. 
There is certainly an argument to improve regulation, as part of a suite of strategies to enhance outcomes for children in out-of-home care. But this cannot be a panacea for the problems of quality of care. There remains much to be done to address demand and supply issues, such as more resources to support families to keep children safely at home, and improved carer support. In regulating care, it would be more productive to develop support mechanisms and partnership models that actively promote a culture of quality and accountability to children. Certainly, the cost of regulation must be contrasted with the minimal supports currently provided, especially for relative carers who provide an increasing proportion of placements. Systems to enable and support carers, such as increasing the time available for professionals to visit placements and provide direct input on the care of the child and listen to the carer's views, would also have the effect of increasing monitoring. The regulation of relative care poses a particular set of problems, being at the intersection of the private and the public (Flynn, 2002). But it would be of concern if the regulation of care in Australia made it more difficult for families to participate in the extended family caring that is central to Aboriginal and Torres Strait Islander family life. The 'gift relationship' at the core of relative care, which is characterised by altruism and reciprocity, should be protected against bureaucratised forms of social care that have no established links to better outcomes (Testa and Slack, 2002). This would require conceptualising relative care as a discrete policy and program area, different to, but still part of, out-of-home care. Instead of grafting the rules for general foster care onto relative care it would be more appropriate to develop a distinct regulatory framework for relative care that is not constrained by a conventional model of foster care and goes beyond procedural approaches to accountability - rather, one that provides support to placements, proactively assisting them to work effectively. 


\section{References}

Ah Kee, M. and Tilbury, C. (1999) 'The Aboriginal and Torres Strait Islander Child Placement Principle is about self determination', Children Australia, 24(3), pp. 4-8.

Ainsworth, F. and Maluccio, A. (1998) 'Kinship care: false dawn or new hope?', Australian Social Work, 51(4), pp. 3-8.

Ashworth, R., Boyne, G., McGarvey, N. and Walker, R. M. (2002) 'Regulating public bodies: the case of direct service organisations in British local government', Environment and Planning C: Government and policy, 20, pp. 455-470.

Batrouney, T., and Soriano, G. (2001) 'Parenting in the Torres Strait Islands', Family Matters, 59, pp. 48-53.

Broad, B., Hayes, R. and Rushforth, C. (2001) Kith and Kin: Kinship care for vulnerable young people, London, National Children's Bureau/Joseph Rowntree Foundation.

Carter, N., Klein, R. and Day, P. (1992) How Organisations Measure Success: The Use of Performance Indicators in Government, London, Routledge.

Cashmore, J. and Paxton, M. (1996) Wards Leaving Care: A longitudinal study, Sydney, NSW Department of Community Services. 
Child Protection and Juvenile Justice Branch (2000) Audit of Kinship Care Clients, Melbourne, Department of Human Services.

Children's Defense Fund (2000) 'Strengthening the safety net: expanding community supports for kinship care families - a kinship care overview', (online) http://www.childrensdefense.org/childwelfare/kinshipcare/safety_net.aspx, 18 April 2005.

Crime and Misconduct Commission Queensland (2004) Protecting children: an inquiry into abuse of children in foster care, Brisbane, Crime and Misconduct Commission.

Cuddeback, G. (2004) 'Kinship family foster care: a methodological and substantive synthesis of research', Children and Youth Services Review, 26(7), pp. 623-639.

Culpitt, I. (1999) Social policy and risk, London, Sage.

Cunneen, C. and Libesman, T. (2000) 'Postcolonial trauma: the contemporary removal of Indigenous children and young people from their families in Australia', Australian Journal of Social Issues, 35(2), pp. 99-116.

Denby, R., Rindfleisch, N. and Bean, G. (1999) 'Predictors of foster parents satisfaction and intent to continue to foster', Child Abuse and Neglect, 23(3), pp. 287-303.

Department of Human Services. (2003) Minimum standards and outcome objectives for home-based care services in Victoria, Melbourne, Child Protection and Juvenile Justice Branch. 
Fisher, T., Gibbs, I., Sinclair, I. and Wilson, K. (2000) 'Sharing the care: the quality sought of social workers by foster carers', Child and Family Social Work, 5(3), pp. 225-233.

Flynn, R. (2002) 'Kinship foster care', Child and Family Social Work, 7(4), pp. 311-321.

Gibbons, L. and Mason, J. (2003) 'Challenges posed by kinship care: a study focusing on NSW', Children Australia, 28(4), pp. 12-18.

Gilbertson, R. and Barber, J. G. (2004) 'The systematic abrogation of practice standards in foster care', Australian Social Work, 57(1), pp. 31-45.

Government of Western Australia. (2005) Protecting children in care: a way forward, Perth, Government of Western Australia.

Henkel, M. (1991) 'The new 'evaluative state", Public Administration, 69(1), pp. 121-136.

Hoggett, P. (1996) 'New modes of control in the public service', Public Administration, 74, pp. 9-32.

Hood, C., James, O., Jones, G., Scott, C. and Travers, T. (1998) 'Regulation inside government: Where new public management meets the audit explosion', Public Money and Management, 18(2), pp. 61-68. 
Human Rights and Equal Opportunity Commission (1997) Bringing them home: report of the National Inquiry into the Separation of Aboriginal and Torres Strait Islander Children from their Families, Sydney, Human Rights and Equal Opportunity Commission.

Kerrison, S. H. and Pollock, A. M. (2001) 'Absent voices compromise the effectiveness of nursing home regulation: a critique of regulatory reform in the UK nursing home industry', Health and Social Care in the Community, 9(6), pp. 490-494.

Leos-Urbel, J., Bess, R. and Geen, R. (2002) 'The evolution of federal and state policies for assessing and supporting kinship caregivers', Children and Youth Services Review, 24(1/2), pp. 37-52.

McHugh, M. (2002) The Costs of Caring: A Study of Appropriate Foster Care Payments for Stable and Adequate Out of Home Care in Australia, Melbourne, Child and Family Welfare Association of Australia, Australian Foster Care Association and the Association of Children’s Welfare Agencies.

Minister for Children, Youth and Family Support (2005) First six-month status report on the implementation of The Territory's Children: Ensuring safety and quality care for children and young people, Canberra.

Munro, E. (2004) 'The Impact of Audit on Social Work Practice', British Journal of Social Work, 34(8), pp. 1075-1095. 
Parker, R., Ward, H., Jackson, S., Aldgate, J. and Wedge, P. (Eds.). (1991). Looking After

Children: Assessing Outcomes in Child Care, London, HMSO.

Peters, J. (2005) 'True ambivalence: child welfare workers' thoughts, feelings, and beliefs about kinship foster care', Children and Youth Services Review, 27(6), pp. 595-614.

Power, M. (1997) The Audit Society: Rituals of Verification, Oxford, Oxford University Press.

Qureshi, H., Berridge, D. and Wenman, H. (2000) Where to turn: family support for South Asian families, London, NCB/Joseph Rowntree Foundation.

Ryburn, M. (1998) 'A new model of welfare: re-asserting the value of kinship for children in state care', Social Policy and Administration, 32, pp. 28-45.

Sanderson, I. (1998) 'Beyond performance measurement? Assessing 'value' in local government', Local Government Studies, 24(4), pp. 1-25.

Scannapieco, M., Hegar, R. and McAlpine, C. (1997) 'Kinship care and foster care: a comparison of characteristics and outcomes', Families in Society, 78(5), pp. 480-488.

Steering Committee for the Review of Commonwealth/State Service Provision (2005) Report on Government Services 2005, Canberra, Productivity Commission.

Sinclair, I. and Wilson, K. (2003) 'Matches and Mismatches: The contribution of carers and children to the success of foster placements', British Journal of Social Work, 33(7), pp. 871884. 
Sinclair, I., Gibbs, I. and Wilson, K. (2004) Foster Carers: Why They Stay and Why They Leave, London, Jessica Kingsley Publishers.

Spence, N. (2004) 'Kinship care in Australia', Child Abuse Review, 13, pp. 263-276.

Stevenson, O. (1992) 'Social work intervention to protect children: aspects of research and practice', Child Abuse Review, 1, pp. 19-32.

Stanley, J., Tomison, A., and Pocock, J. (2003) 'Child abuse and neglect in Indigenous Australian communities', Child Abuse Prevention Issues, 19, pp. 1-31.

Testa, M. F. and Slack, K. S. (2002) 'The gift of kinship foster care', Children and Youth Services Review, 24(1/2), pp. 79-108.

Thoburn, J. and Sellick, C. (2002), 'Family Placement Services', in McNeish, D., Newman, T. and Roberts, H. (Eds.), What Works for Children? Effective Services for children and families, Buckingham, Open University Press.

Triseliotis, J., Borland, M. and Hill, M. (2000) Delivering Foster Care, London, BAAF.

Walshe, K. (2003) Regulating Healthcare, Maidenhead, Open University Press.

Waterhouse, S. and Brocklesby, E. (1999), 'Placement choices for children - giving more priority to kinship placements?', in Greeff, R. (Ed.), Fostering Kinship, Aldershot, Ashgate. 
